\title{
Generalized head movement
}

Karlos Arregi \& Asia Pietraszko*

\begin{abstract}
We argue for a unified account of head movement and lowering in which lowering is in essence the covert movement counterpart of head movement. This proposal is supported by the existence of successive cyclic lowering (evidenced by relative prefix formation in Ndebele), in which complex heads built by lowering have the Mirror-Principle-obeying structure expected under a head movement derivation. It also predicts that lowering can feed head movement, giving the appearance of long head movement, which we argue is the case in Mainland Scandinavian V2.
\end{abstract}

Keywords. head movement; lowering; Mirror Principle; Head Movement Constraint; V2; ellipsis; do-support; relative clauses; vowel coalescence; Ndebele; Danish

1. Introduction. Since at least Emonds 1970, two similar types of movements relating head positions (terminal nodes) have been distinguished in the literature. Their differences can be illustrated with the distribution of finite lexical (nonauxiliary) verbs in French and English. While in the former $\mathrm{V}$ moves out of VP to a higher (c-commanding) head position hosting finite inflection (represented here as T), lexical V in English stays in situ, and instead T lowers into V's VPinternal position, ${ }^{1}$ as diagnosed, for instance, by the relative position of the finite verb with respect to adverbs adjoined to the left of VP (Chomsky 1957, Emonds 1970:211-226, 1978:65-68, Pollock 1989): ${ }^{2}$

\section{(1) $\quad V$ to $T$ raising in French}

Jean $\{*$ souvent embrasse / embrasse souvent $\}$ Marie.

Jean often kisses / kisses often Marie

'Jean often kisses Marie.'

Pollock 1989:367

T to V lowering in English

Sue $\{$ often eats / *eats often $\}$ fish.

These two movements are often taken to illustrate two different kinds of operations: the raising type is an instance of syntactic Head Movement in the sense of Koopman 1984, Travis 1984, and Baker 1988, while the lowering type is postsyntactic (Halle \& Marantz 1993:132-138, Bobaljik 1995:57-109, and Embick \& Noyer 2001, based on ideas in Lasnik 1981).

We propose instead a unification of the two types of movement under a single operation of Generalized Head Movement (GenHM). As defined in section 2, GenHM is a transformation that relates two head positions and results in complex head copies with the same internal structure in the two positions, with rules of copy pronunciation determining whether the surface result

\footnotetext{
* We thank the audience at the 2018 Annual Meeting of the LSA for their helpful feedback on our work. This research was partly funded by the National Science Foundation (BCS-1551787). Authors: Karlos Arregi, University of Chicago (karlos@uchicago.edu) \& Asia Pietraszko, University of Connecticut (joanna.pietraszko@uconn.edu). ${ }^{1}$ For the purposes of this paper, we remain agnostic as to the exact position of the finite verb in English, which could be $\mathrm{V}$, v, or Voice, or even higher, but in any case, lower than $\mathrm{T}$ and adverbs such as often. For ease of exposition, we represent this position as $\mathrm{V}$ and to its phrasal projections as VP. If it turns out that the verb is in a higher position, our analysis below should be modified to include further GenHM steps moving V to this higher position. Similar comments apply to our analysis of verb movement in Mainland Scandinavian in section 4.

${ }^{2}$ We follow the Leipzig Glossing Rules (https://www.eva.mpg.de/lingua/resources/glossing-rules.php), with the addition of the abbreviations DSJ (disjoint), REL (relative subject prefix) and cardinal numerals denoting noun classes in the Ndebele examples.
} 
is raising or lowering. A unified treatment has precedents in the theory of Minimalist Grammars (Stabler 2001), and in Harizanov \& Gribanova 2018, and is one of the defining features of Mirror Theory (Brody 2000, Adger et al. 2009, Svenonius 2016). However, the formalization proposed here differs substantially from those works, and, for reasons of space, we cannot undertake a detailed comparison here, which we leave for future work.

Our overarching argument for GenHM (or any unified analysis that makes similar predictions) is that head raising and lowering have the same properties: both are cyclic, resulting in complex heads with the same type of internal structure, and both can feed further instances of head movement. Our first specific argument, presented in section 3, comes from Ndebele relative clauses, in which we argue that a complex head composed of Lnk, D, C, and T is pronounced in the lowest position of the head chain (T), yet its internal structure obeys Baker's (1985) Mirror Principle: [Lnk [D [C T]]], as shown by the surface phonological form of this complex head. This is expected if cyclic head lowering generates the same type of structures as head raising, as predicted by GenHM. The second argument for GenHM (section 4) is based on the prediction that lowering of a head to another head can feed raising of the resulting complex head to a higher head position, giving the appearance of long or noncyclic head movement. We argue that this is the case in V2 sentences in some North Germanic languages, in which movement from $\mathrm{V}$ to $\mathrm{C}$ appears to skip an intermediate step in $\mathrm{T}$. More specifically, we argue that V-to-C movement in these languages is actually T-to- $\mathrm{C}$ raising fed by T-to-V lowering, a cyclic sequence of local operations allowed by GenHM. The main advantage of this analysis with respect to previous head-movement-based accounts is that no step in our derivation violates independently motivated cyclicity or locality constraints.

2. Generalized Head Movement. We define GenHM as an operation that relates a head with the head of its complement, resulting in copies of the same complex head in both positions. The operation is triggered by a feature on the higher head, notated here with a superscripted $\mathrm{hm}$. Importantly, the output structure is neutral between raising and lowering, as the complex head is represented in both positions. The operation also creates a head chain, which keeps track of the positions related by GenHM and the internal structure of the complex head: ${ }^{3}$

\section{Generalized Head Movement}

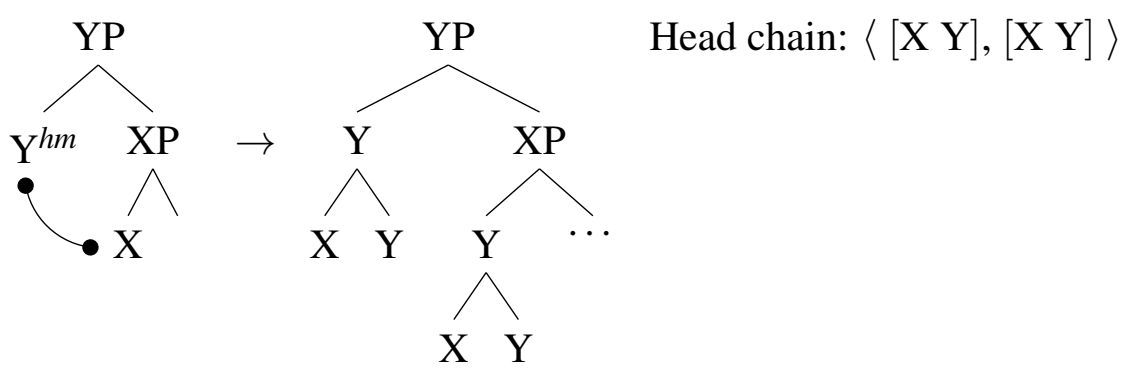

\footnotetext{
${ }^{3}$ The representation in (3) abstracts away from linear order: $\mathrm{Y}$ can be linearized to the left or right of its complement XP, and the order of the elements in the complex head can be either XY or YX. These choices are governed by language and lexical item-specific parameters, not discussed here. We assume that the nonterminal nodes in the complex head are the same in all copies (e.g. Y in (3)). We do not consider this an indispensable aspect of our account, and are open to other options, such as labeling the root node of each copy according to its specific position (i.e. Y for the higher copy and $\mathrm{X}$ for the lower copy in (3)). We are not aware of any differences in empirical predictions between the different options. On the other hand, the labels on the terminal nodes, as well as their mutual hierarchical relations must be as shown, as this ensures that the complex head obeys the Mirror Principle.
} 
Another defining property of GenHM, represented in (4), is that further instances of the operation result in copies of the same complex head in all head positions related by the operation.

Further application of GenHM generates identical copies in all positions
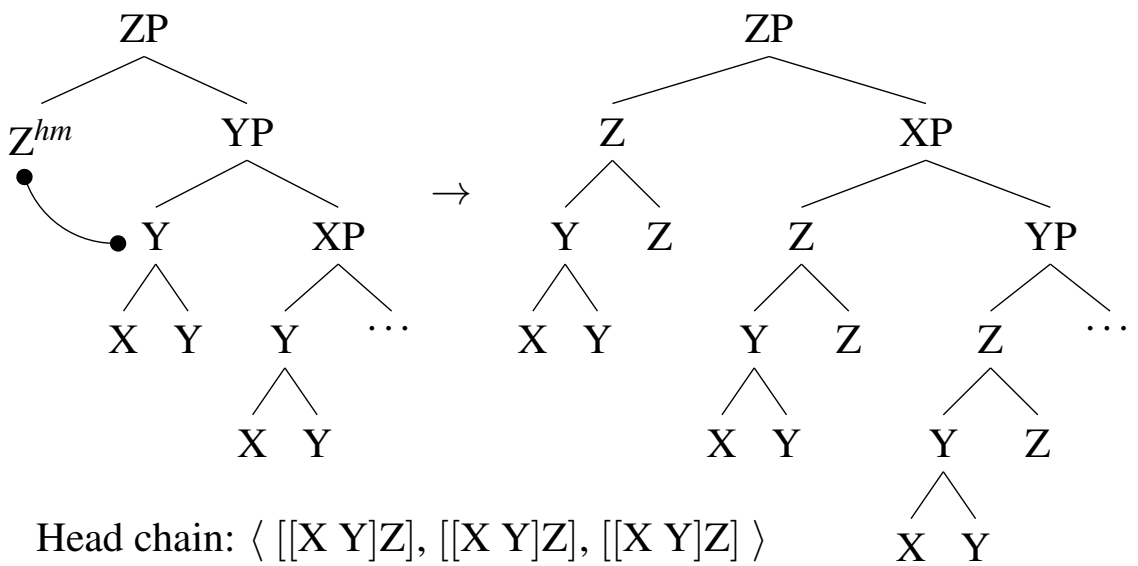

Head chain: $\langle[[\mathrm{X} Y] \mathrm{Z}],[[\mathrm{X} Y] \mathrm{Z}],[[\mathrm{X} \mathrm{Y}] \mathrm{Z}]\rangle$

As should be clear from the description above, GenHM derives Mirror Principle effects by incorporating the Head Movement Constraint (HMC) and the ban on excorporation (Travis 1984, Baker 1985, 1988).

A key feature of GenHM is that head raising and lowering are the result of the same syntactic operation - one which creates copies of the resulting complex head in multiple positions. Under this view, lowering is essentially covert head movement, that is, pronunciation of a lower copy. We implement this aspect of the account in terms of lexical diacritic features on specific head positions that govern the application of postsyntactic spellout rules: ${ }^{4}$

(5) A head position can be strong $\left(\mathrm{X}^{*}\right)$ or weak. ${ }^{5}$

(6) Spellout of head chains

a. Pronounce the highest strong position, if any;

b. otherwise, pronounce the highest position.

This type of parametrization can be illustrated by the contrasting behavior of finite verbs in French and English. In both, GenHM relates T and V, triggered by $h m$ on $\mathrm{T}$ and placing copies of the complex head [V T] in both head positions. Both $\mathrm{T}$ and $\mathrm{V}$ are weak in French, hence the finite verb is pronounced in the higher position (T) by (6b). In English, T is weak as well, and so is V when it is be or (auxiliary) have, but all other Vs are strong. As a result, finite be and have are spelled out in the higher position (by (6b)), but all other finite verbs are pronounced in the only strong position in the chain, namely $\mathrm{V}$ (by (6a)). ${ }^{6}$

3. Successive cyclic lowering in Ndebele. Any theory of head movement must capture the generalization that the internal structure of the resulting complex head mirrors the syntactic structure

\footnotetext{
${ }^{4}$ This implementation has clear parallels in Mirror Theory (Brody 2000). More specifically, our strong diacritic feature $\left(\mathrm{X}^{*}\right)$ is similar to Svenonius's (2016) @ feature.

${ }^{5}$ GenHM creates copies that are identical in all positions except for $*$, which is only present in the head position it is generated in. This ensures that this feature actually has an effect on the spellout of a head chain.

${ }^{6}$ In this particular case, application of (6a) is trivial, since there is only one strong position in the chain. See section 4 for illustration of the spellout of head chains with more than one strong position.
} 
- the Mirror Principle (Baker 1985). Assuming the Head Movement Constraint and the ban on excorporation, the mirroring effect follows from cyclicity of syntactic operations. In (7), for instance, $\mathrm{XP}$ and YP form a constituent to the exclusion of $\mathrm{ZP}$ and therefore $\mathrm{X}$ and $\mathrm{Y}$ form a constituent to the exclusion of $\mathrm{Z}$ after head movement.

$$
[\mathrm{ZP} Z[\mathrm{YP} \text { Y [XP X ]]] } \stackrel{\mathrm{X} \text {-to-Z head movement }}{\longrightarrow}[\mathrm{Z} \mathrm{Z}[\mathrm{Y} \text { Y X }]]
$$

GenHM derives the Mirror Principle in the same way - it is an operation applying cyclically in a bottom-up fashion, yielding the effect in (7). It additionally makes clear predictions about the internal structure of complex heads formed by lowering: they too are expected to have a fully cyclic internal structure. This is a natural consequence of treating head raising and lowering as outcomes of the same syntactic operation. This section presents an argument that lowering indeed creates complex heads that obey the Mirror Principle, supporting the proposed unification of head raising and lowering. ${ }^{7}$

The argument comes from the formation of relative agreement prefixes in Ndebele (Bantu, S44). In Ndebele, the subject agreement prefix on the verb has a special form in relative clauses (RCs). Compare the regular subject agreement prefix for class 7 with its counterpart in a RCinternal verb:

$$
\begin{aligned}
& \text { Regular subject prefix (Sbj-Agr) } \\
& \text { Isi-lwane si-za-gijima. } \\
& \text { 7-lion 7SBJ-FUT-run } \\
& \text { 'The lion will run' }
\end{aligned}
$$

(9) Relative subject prefix (Rel-Agr)

$$
\begin{aligned}
& \text { isi-lwane [RC esi-za-gijima ] } \\
& \text { 7-lion [RC 7REL-FUT-run] } \\
& \text { 'the lion that will run' }
\end{aligned}
$$

It has been recognized in the Bantu literature that the relative agreement prefix is not monomorphemic and contains a regular subject agreement prefix plus some other morphology. In some languages, the additional component has been identified as the associative linker a- (Khumalo 1992, Demuth \& Harford 1999, Cheng 2006, Zeller 2004, Henderson 2006, Taraldsen 2010); ${ }^{8}$ in others, as the so called augment vowel, a nominal prefix (Cheng 2006, Diercks 2010, Henderson 2013). Pietraszko (2017) shows, on the basis of morphosyntactic and phonological evidence, that Ndebele relative prefixes contain all three morphemes: a regular agreement prefix, an augment vowel and the associative linker.

As shown in (10), we adopt the standard view of the augment vowel as a determiner (von Staden 1973, Giusti 1997, de Dreu 2008, Visser 2008, among many others), and treat it as an exponent of D. Thus, a relative CP (whose head is null) is dominated by a DP shell, headed by an augment vowel. This analysis of RCs is supported by the observation that all embedded clauses in the language are contained in a DP shell (see Pietraszko 2017 for evidence) and the fact that RCs attach to the head noun the same way other DPs (e.g. possessors) do - they are introduced by the associative linker $a$. Finally, the decomposition in (10) derives Rel-Agr prefixes from regular phonological rules, as we will see shortly.

\footnotetext{
${ }^{7}$ The same predictions are made by Mirror Theory. For instance, Adger et al. (2009)'s Mirror-Theoretic analysis of Kiowa accounts for the fact that complex verbal heads that are pronounced low have a Mirror-Principle obeying internal structure. A yet different implementation of cyclic lowering can be found in Harizanov \& Gribanova (2018). In their theory, lowering of $\mathrm{Y}$ to $\mathrm{X}$ removes $\mathrm{Y}$ from its original position, making it possible for a higher head to lower to $\mathrm{X}$ directly. Unlike Mirror Theory and GenHM, this theory does not derive the cyclicity of raising and lowering in a uniform way as it does not unify these two operations.

${ }^{8}$ The linker is sometimes referred to as associative marker, possessive marker or relative marker in the literature.
} 
(10)

The components of a Rel-Agr prefix

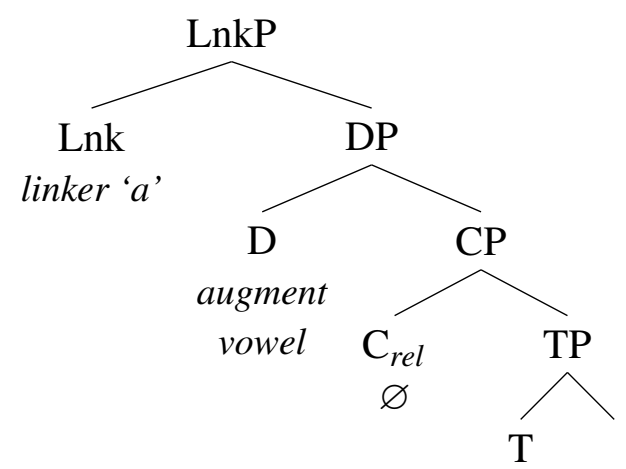

Sbj-Agr

As an illustration, consider the Rel-Agr prefix of class 7 esi in (9). It consists of the linker $a$, an augment vowel and the regular agreement prefix si-, located in T:

(11) The components of the class 7 Rel-Agr 'esi-'

[NP 7lion [LnkP Lnk [DP $\mathrm{D}_{\varphi: 7}$ [CP $O p_{i} \mathrm{C}\left[{ }_{\mathrm{TP}} t_{i} \mathrm{~T}_{\varphi: 7}\right.$ [vP run ]]]]]]

$$
\text { a } \quad i \quad \text { si } \rightarrow \text { esi }
$$

Since the D head in RCs always covaries with the class of the RC-internal subject, its exponent in (11) is the augment vowel for class $7 i$. The three morphemes, $a+i+s i$, surface as $e s i$ as a result of regular phonological processes (see below for details).

We argue that the formation of relative agreement prefixes in Ndebele is an instance of cyclic lowering. GenHM applies bottom up to T, C, D and Lnk, creating identical complex heads in all positions in the chain. $\mathrm{T}^{*}$ is the only, hence highest, strong position, therefore the resulting complex head is pronounced in $\mathrm{T}^{*}$ :

\section{Lnk, $D$ and $C$ are weak; $T^{*}$ is strong}

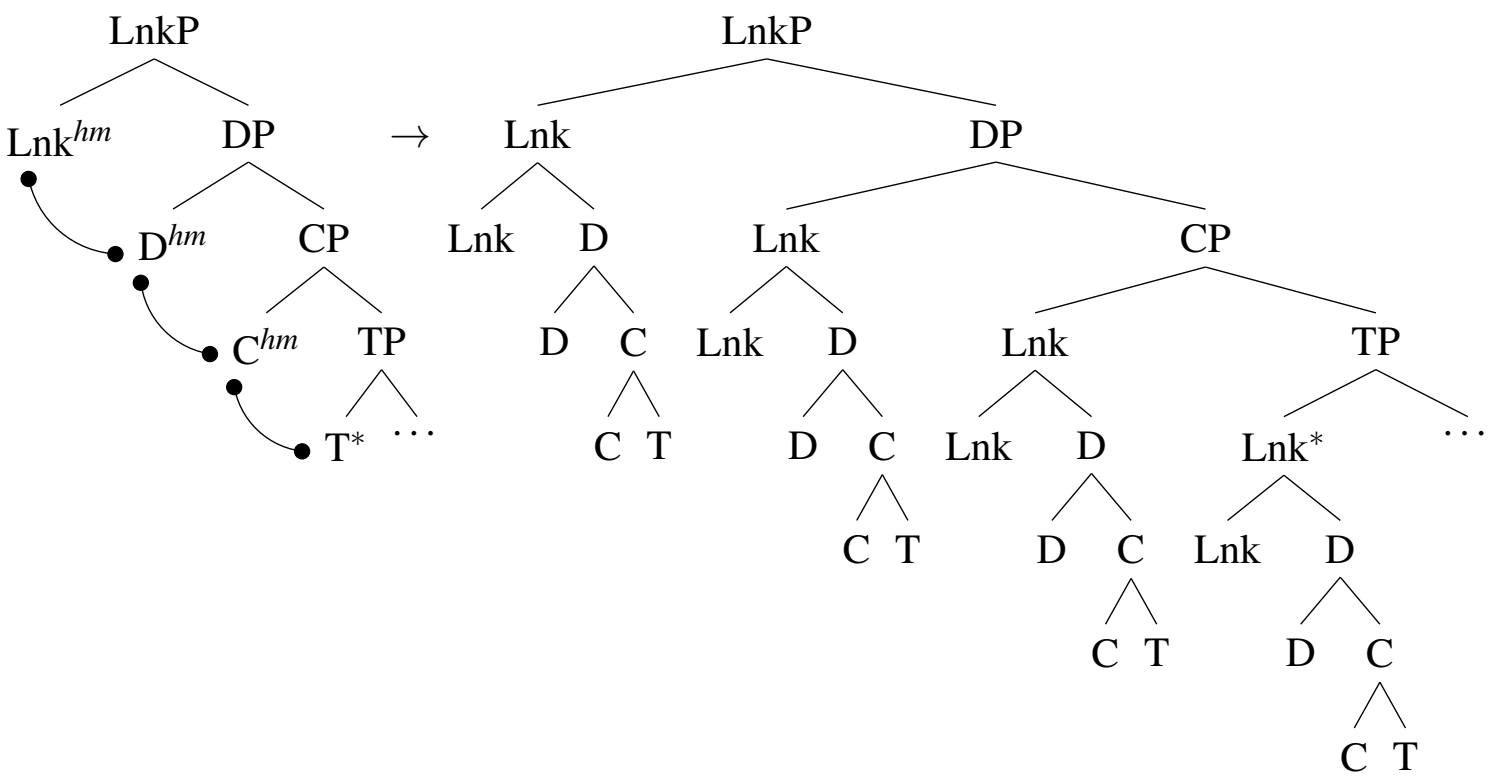

Note that the internal structure of the complex head in TP obeys the Mirror Principle (T and C 
form a constituent to the exclusion of D, etc.), which follows from cyclic application of GenHM. Evidence for the low spellout position of the Rel-Agr complex head comes from object RCs with overt RC-internal subjects, as in (13). The crucial fact is that all components of the RelAgr prefix follow the subject isilwane 'lion'. Assuming that the subject is in Spec,TP, as shown in (14), the linker and the augment vowel must lower across the subject to a position where they can be linearized to its right.

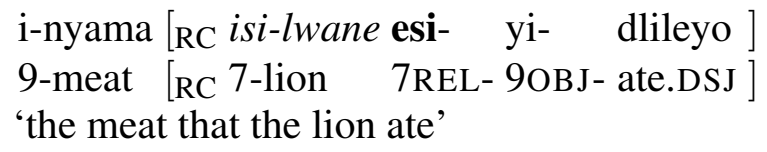

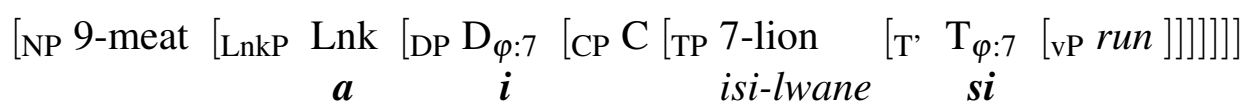

A different explanation of similar facts in Zulu is proposed by Henderson $(2006,2007)$, who treats Rel-Agr as created by head raising, rather than lowering. Henderson proposes that the reason the RC-internal subject precedes all components of the Rel-Agr prefix is because it is structurally higher than all these components - it is a left-dislocated topic. While preverbal subjects in Bantu languages typically behave like topics (Bresnan \& Mchombo 1987, Baker 2003, Letsholo 2002), it is not universally so. Crucially, RC-internal subjects in Ndebele do not have the topical properties of matrix subjects. ${ }^{9}$ This is evident from the contrast between (15) and (16), where the focus particle only is used as a diagnostic for a focus (i.e. non-topic) interpretation of the subject. As we see, a matrix subject cannot be in focus (15) but a RC-internal subject can (16).

Matrix subject: *focus

*Aba-fana kuphela ba-dla i-suphu.

2-boys only 2sBJ-eat 7-soup

'Only boys eat soup.'
$R C$-internal subject: $\checkmark$ focus
i-suphu [RC aba-fana kuphela aba-si-dlayo
7-soup [RC 2-boys only 2REL-7OBJ-eat.DSJ ]
'the soup that only boys eat'

The possibility of focusing a RC-internal subject suggests that, unlike a matrix subject, it is not a left-dislocated topic. Importantly, even under its focused interpretation, the subject precedes all components of Rel-Agr, supporting the lowering view.

There is evidence that the Rel-Agr complex head, pronounced in a low position, has the internal structure predicted for heads created by head raising - it mirrors the syntactic structure. The evidence is phonological. Rel-Agr is formed by bottom-up application of regular vowel coalescence rules (Sibanda 2004), given in (17), and illustrated for some noun classes in (18).

Vowel coalescence rules
a. $\mathrm{V}_{\alpha}+\mathrm{V}_{\alpha} \rightarrow \mathrm{V}_{\alpha}$
b. $\mathrm{a}+\mathrm{i} \rightarrow \mathrm{e}$
c. $\mathrm{a}+\mathrm{u} \rightarrow \mathrm{o}$
d. $\mathrm{e}+\mathrm{V}_{\alpha} \rightarrow \mathrm{V}_{\alpha}$

\begin{tabular}{llllll}
\multicolumn{4}{c}{ class $\left[\mathrm{Lnk}\left[\mathrm{D}_{\varphi}\left[\mathrm{C} \mathrm{T}_{\varphi}\right]\right]\right]$} & $\rightarrow \mathrm{REL}$ \\
\hline 1 & $\mathrm{a}$ & $\mathrm{u}$ & $\mathrm{u}$ & $\rightarrow[\mathrm{a}[\mathrm{u}]]$ & $\rightarrow \mathrm{o}$ \\
9 & $\mathrm{a}$ & $\mathrm{i}$ & $\mathrm{i}$ & $\rightarrow[\mathrm{a}[\mathrm{i}]]$ & $\rightarrow \mathrm{e}$ \\
7 & $\mathrm{a}$ & $\mathrm{i}$ & $\mathrm{si}$ & $\rightarrow[\mathrm{a}[\mathrm{isi}]]$ & $\rightarrow \mathrm{esi}$ \\
11 & $\mathrm{a}$ & $\mathrm{u}$ & $\mathrm{lu}$ & $\rightarrow[\mathrm{a}[\mathrm{ulu}]] \rightarrow \mathrm{olu}$
\end{tabular}

${ }^{9}$ Similar constraints on topical vs. focal subjects are discussed e.g. by Schneider-Zioga (2007) for Kinande. 
The order in which coalescence rules apply is determined by the internal structure of the complex head. Their application is cyclic - it targets the two most embedded components first and so on, as indicated by the bracketing in (18). Crucially, the surface form of Rel-Agr can be correctly derived by regular phonology only if the internal structure of the complex head obeys the Mirror Principle. Consider the derivation of class 9 Rel-Agr:

Cyclic derivation of class 9

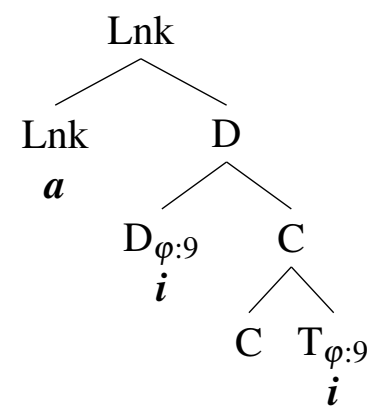

$[\mathrm{a}[\mathrm{i}$ i $]] \underset{(17 \mathrm{a})}{\stackrel{\mathrm{by}}{\longrightarrow}}[\mathrm{a}[\mathrm{i}]] \underset{(17 \mathrm{~b})}{\stackrel{\text { by }}{\longrightarrow}} \mathrm{e}$

\section{(20)}

Noncyclic derivation of class 9

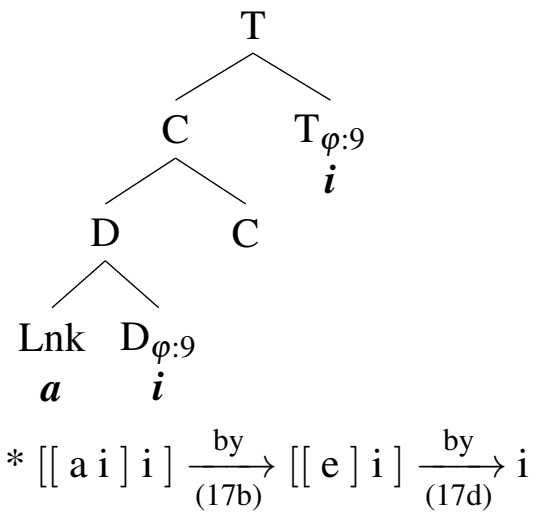

While the Mirror-Principle-obeying structure derives the correct form $e$ (19), the non-mirroring bracketing in (20) incorrectly predicts the form $i$ for the class 9 Rel-Agr prefix.

We conclude that Rel-Agr prefixes in Ndebele are formed by cyclic lowering. They are complex heads whose internal structure is identical to the internal structure of complex heads created by head raising (they obey the Mirror Principle), but whose pronunciation is in a low position. Cases like this are possible under GenHM, where head raising and lowering are the same syntactic process and differ only in copy pronunciation.

4. Lowering feeds raising in Mainland Scandinavian V2. In this section, we explore the predictions of the account with respect to head chains that contain more than one strong position. In particular, consider a head chain in which the strong positions are not structurally adjacent:

$$
\left[\mathrm{ZP} \mathrm{Z}^{h m, *}\left[\mathrm{YP} \mathrm{Y}^{h m}\left[\mathrm{XP} \mathrm{X}^{*}\right]\right]\right]
$$

Descriptively, this case will look as if lowering from intermediate $\mathrm{Y}$ to low $\mathrm{X}$ feeds raising of the complex head $[\mathrm{X} \mathrm{Y}]$ to the highest position in $\mathrm{Z}$. In other words, in the absence of $\mathrm{Z}$, the result is lowering of $\mathrm{Y}$ to $\mathrm{X}$, but if $\mathrm{Z}$ is present, it looks like raising to the highest position. Under this distribution of strong features, the complex head is pronounced in the highest position in some cases and in the lowest position in others, but never in the intermediate position. The surface effect is thus one in which the lowest and highest positions seem to be related in a nonlocal or noncyclic way, yet each step involves an application of GenHM that is both cyclic and local, since at each step a head is related to the head of its complement, and GenHM in a lower part of the structure precedes GenHM in a higher part of the structure. We argue that this is precisely the case in V2 sentences in the North Germanic languages of Mainland Scandinavia (MSc; Danish, Norwegian, and Swedish). We exemplify the phenomenon throughout with examples from Danish.

The basic puzzle posed by V2 in MSc is that, although V moves to C in V2 contexts, there is no independent evidence for an intermediate step of this movement in T (i.a. den Besten 1983, Taraldsen 1985, Holmberg 1986, Platzack 1986, Holmberg \& Platzack 1995, Vikner 1995). First, $\mathrm{V}$ is in $\mathrm{C}$ in $\mathrm{V} 2$ contexts, as diagnosed by the position of the finite verb to the immediate left of 
the subject:

(22) Om morgenen drikker [TP Peter [VP ofte kaffe ]] in the.morning drinks [TP Peter [VP often coffee ]] 'Peter often drinks coffee in the morning.'

Vikner 1995:47

Second, in non-V2 sentences, the position of the finite verb to the left of markers of the left edge of VP (e.g. adverbials) reveals that the former surfaces within VP: ${ }^{10}$

(23) Vi ved at [TP Peter [VP ofte drikker kaffe om morgenen ]] we know that [TP Peter [VP often drinks coffee in the.morning ]]

'We know that Peter often drinks coffee in the morning'

Vikner 1995:47

This paradigm thus illustrates the case described above: the complex head is spelled out in the highest position $(\mathrm{C})$ under $\mathrm{V} 2$ and in the lowest position $(\mathrm{V})$ otherwise, but never in the intermediate position $(\mathrm{T})$.

Previous head-movement-based analyses of this pattern sacrifice either cyclicity or locality. In Holmberg \& Platzack 1995:49-50 and Vikner 1995:28-31, 133, cyclicity is sacrificed for the sake of locality, as they propose that $\mathrm{V}$ raises to $\mathrm{T}$ only if there is further movement to $\mathrm{C}$ : $\mathrm{V}$ does not move to T overtly in non-V2 contexts, ${ }^{11}$ and in V2 sentences, V moves to $\mathrm{C}$ making an intermediate step in T enforced by locality (HMC). This is a non-cyclic account, in the sense that Vto-T movement is contingent on further movement from $\mathrm{T}$ to $\mathrm{C}$, and thus does not solely depend on properties of $\mathrm{V}$ and T. On the other hand, Harizanov \& Gribanova 2018 preserve cyclicity, but propose that $\mathrm{V}$ moves to $\mathrm{C}$ directly, not constrained by the HMC. ${ }^{12}$

In contrast to these analyses, GenHM allows for a derivation of this paradigm that is strictly cyclic and local, as it instantiates the abstract pattern in (21): both the highest (C) and lowest (V) head positions are strong, and the intermediate position $(\mathrm{T})$ is weak. In non-V2 contexts, C does not trigger GenHM, and only $\mathrm{V}$ and $\mathrm{T}$ are involved:

Non-V2 derivation: weak $T$ and strong $V^{*}$

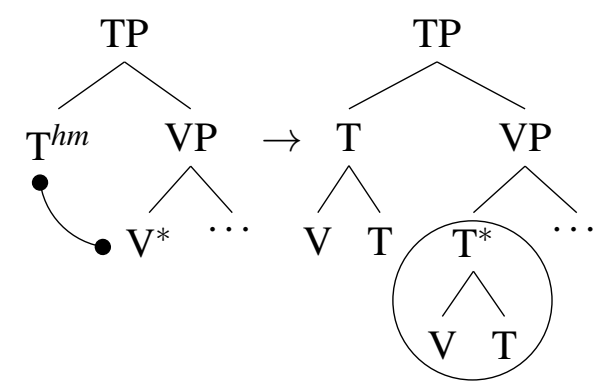

\footnotetext{
${ }^{10}$ On the precise position of the finite verb in non-V2 contexts, see footnote 1 . Unlike English, all verbs, including auxiliaries, surface in a low position in non-V2 contexts (see references cited above for evidence). Under the GenHM account presented below, this entails that auxiliaries are generated in strong head positions.

${ }^{11}$ In addition, $\mathrm{V}$ and $\mathrm{T}$ are related by either lowering or a lexicalist feature-checking operation and LF movement, along the lines of Chomsky 1993.

12 In Harizanov \& Gribanova 2018, T and V are related by postsyntactic lowering, under a partially unified analysis of postsyntactic raising and lowering head movement that is similar to our proposal in many respects. Crucially, under their proposal, the direct movement of $\mathrm{V}$ to the $\mathrm{C}$ domain in $\mathrm{V} 2$ contexts is not due to these postsyntactic processes, which are subject to HMC-like locality.
} 
Since $\mathrm{V}$ is the highest - in fact, the only - strong position, the complex head is spelled out within VP. The derivation in V2 contexts involves a further step of GenHM relating T and C:

V2 derivation: strong $C^{*}$, weak $T$, and strong $V^{*}$
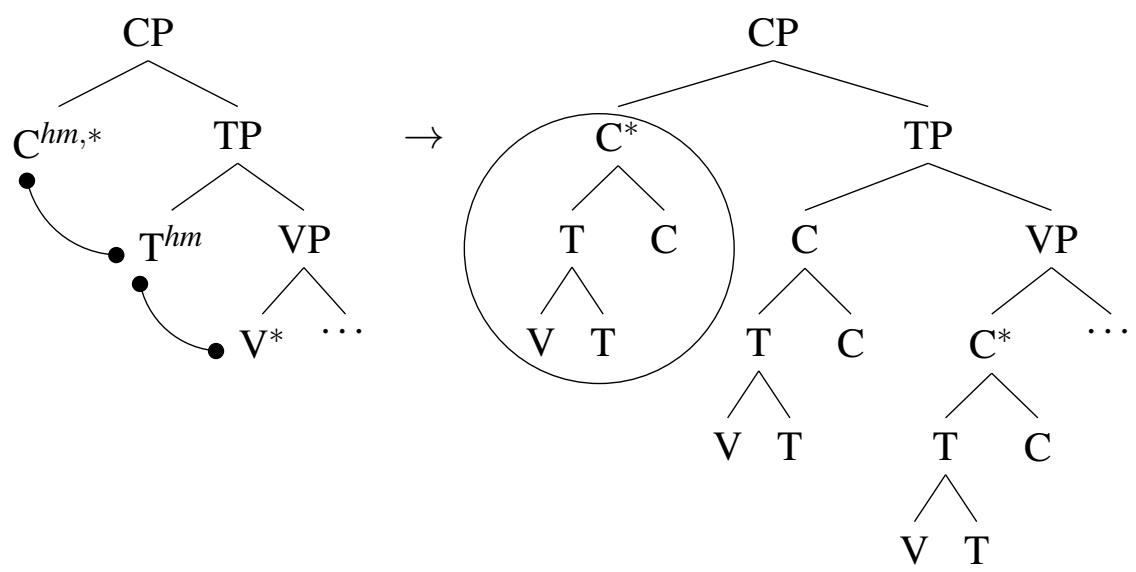

In this case, the highest strong position is in $\mathrm{C}$, which is where the complex head is spelled out. The surface effect is the appearance of lowering from $\mathrm{T}$ to $\mathrm{V}$ followed by movement from $\mathrm{V}$ to $\mathrm{C}$ either in one long step or countercyclically stopping in T. However, each step in the syntactic derivation is local and cyclic: the first instance of GenHM relates $\mathrm{T}$ and $\mathrm{V}$, and the second, $\mathrm{C}$ and T. The apparent nonlocality or noncyclicity of the derivation is due to the fact that the strong positions (V and C) are not structurally adjacent. ${ }^{13}$

In the rest of this section, we address two potential challenges to the claim that V2 derivations in MSc are local and cyclic in the sense described above. The first comes from comparison with movements of heads that have been argued to not obey the HMC. We concentrate here on the phenomenon of participle fronting found in a number of South and West Slavic languages (i.a. Lema \& Rivero 1990, Embick \& Izvorski 1997, Harizanov \& Gribanova 2018; all examples below are from Bulgarian). In this construction, a participle generated below an auxiliary (26a) is displaced to the left of the intervening auxiliary (26b).

(26) Participle fronting across an intervening auxiliary

Harizanov \& Gribanova 2018:17
a. Bjah pročel knigata.
b. Pročel bjah knigata.
had read.PTCP the.book
read.PTCP had the.book
'I had read the book.'
'I had read the book.'

Skipping an intervening head position (the auxiliary) is evidence that the movement is not subject to the HMC. This is confirmed by examples in which a participle skips more than one auxiliary (27), one of which can itself be a participle (28).

Participle fronting across two intervening auxiliaries Harizanov \& Gribanova 2018:17
a. Šte săm pročel knigata.
b. Pročel šte săm knigata.
will have read.PTCP the.book
read.PTCP will have the.book
'I will have read the book.'
'I will have read the book.'

\footnotetext{
${ }^{13}$ The idea that the apparent locality or noncyclicity problems in V2 in MSc dissolve once we view this as a matter of determining the spellout positions of heads is due to Svenonius 2016:217-218.
} 
(28) Participle fronting across an intervening participle

Embick \& Izvorski 1997:231
a. Bihte bili arestuvani ot policijata. would been arrest.PTCP by the.police
'You would be arrested by the police.'
b. Arestuvani bihte bili ot policijata. arrest.PTCP would been by the.police 'You would be arrested by the police.'

These and other cases of clear long head movement (not discussed here) provide evidence that there is a type of head movement that is not constrained by the HMC. The (apparent) nonlocality of V2 movement in MSc can in turn be seen as evidence that it is another example of this type of long head movement, as proposed in Harizanov \& Gribanova 2018.

We submit that this is not the right conclusion. Unlike participle fronting in Slavic, V2 movement in MSc does not skip intervening verbs. Only the highest verb, that is, the one bearing $\mathrm{T}$ inflection, can be fronted in MSc:

(29) In V2 sentences, $C$ attracts the $V$ with finite $T$
a. Her har Peter ikke sovet.
b. *Her sovet Peter ikke har. here has Peter not slept. 'Peter has not slept here.' here slept Peter not has 'Peter has not slept here.'

Vikner 1995:31

This is as expected if $\mathrm{V} 2$ is movement from $\mathrm{T}$ to $\mathrm{C}$, as in the GenHM analysis presented above. The only indication that V2 violates the HMC is the fact that V never surfaces in $\mathrm{T}$ in MSc, but as shown above, this is compatible with an analysis in terms of HMC-respecting head movement. We thus conclude that there is no evidence that V2 movement violates the HMC.

The second challenge comes from the interaction of V2 with VP ellipsis (VPE), which, according to Sailor (2009, to appear), supports the view that V-to-C movement is countercyclic. Since VPE is possible in MSc (Sailor 2009, Houser et al. 2011, Thoms 2012, Bentzen et al. 2013), one might expect these languages to display V-stranding VPE in V2 environments, that is, sentences in which a verb is not elided along with the rest of the VP because of V-movement to C. This, however, is not the case, as a lexical finite verb cannot surface in second position in a V2 sentence (Sailor 2009, Thoms 2012), and the V2 requirement is instead satisfied by a dummy auxiliary translatable as 'do' (gфre in Danish):

In VPE+V2 contexts, lexical Vs don't surface in $C$

*Mona og Jasper vaskede bilen, eller rettere Mona vaskede. Mona and Jasper washed the.car or rather Mona washed 'Mona and Jasper washed the car, or rather Mona did.'

Sailor, to appear, (7a)

(31) In these contexts, $C$ is occupied by gøre

Mona og Jasper vaskede bilen, eller rettere Mona gjorde

Mona and Jasper washed the.car or rather Mona did

Mona and Jasper washed the car, or rather Mona did.'

Houser et al. 2011:249

Sailor takes examples such as (30) to be evidence that VPE prevents movement of V to C. The account relies on two crucial assumptions. First, following Aelbrecht 2010, ellipsis applies at the stage of the syntactic derivation that the licensing head is merged with the constituent containing the target of ellipsis, and makes elided material inaccessible to subsequent operations, including movement (in the case of VPE, the licensing head is T, and the elided constituent is VP). The second assumption is that in V2 in MSc, C attracts V (not T) directly when the former is merged 
(with a possible countercyclic step in T enforced by locality). The derivation of (30) thus proceeds as follows:

Blocked derivation of VPE $+V 2$ in (30) in Sailor, to appear
a. T triggers VPE; no V-movement
b. C can't attract $V$ from elided $V P$
$[$ TP $\mathrm{T}$ [VP $\mathrm{V}$ DP $]$ ]

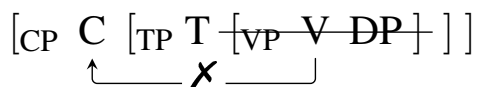

First, T is merged and triggers ellipsis of VP (32a). At this stage, V does not move out of VP, since, by hypothesis, V2 movement is triggered when $\mathrm{C}$ is merged (and other than in V2, V stays in situ in MSc). When C is merged (32b), this head attracts a V, but the lexical verb in VP is not accessible to syntactic operations at this point. Importantly, the head triggering VPE (T) is merged before the head triggering movement of $\mathrm{V}(\mathrm{C})$, which results in ellipsis bleeding movement. ${ }^{14}$ This contradicts one of our main claims about V2 in MSc, namely, that it involves a cyclic step relating $\mathrm{T}$ and $\mathrm{V}$.

In contrast, we claim that the VPE facts are compatible with a cyclic and local analysis of V2, as predicted by our GenHM analysis. Our counterargument is based on the observation that a verb does move to $\mathrm{C}$ in VPE sentences subject to the V2 requirement (Houser et al. 2011). Although a finite lexical verb does not appear in this position, what surfaces there instead is the dummy auxiliary gфre 'do', as shown in (31) above. Crucially, this auxiliary is present under VPE even in the absence of the V2 requirement:

$V P E$ requires gøre-support even in non-V2 contexts

Houser et al. 2011:251-252

Der er en forventning om, at vi skal gå videre, selv om det snarere vil være en stor there is an expectation about that we shall go further even if it rather will be a big skuffelse end katastrofalt, [ hvis vi ikke $g \phi r$ ] disappointment than catastrophic [ if we not do ]

'We are expected to go further (in the competition). That said, it would be a great disappointment, not a catastrophe, if we don't.'

The bracketed embedded sentence in (33) involves ellipsis of a VP headed by a finite lexical verb, and, accordingly, auxiliary gфre is needed. However, this type of embedded sentence is not subject to the V2 requirement, and, accordingly, the auxiliary does not surface in C. In fact, its position after negation reveals that it surfaces below T. Thus, the site of gфre insertion in VPE contexts is quite low, as argued for in Houser et al. 2011, and its presence in C in V2 contexts such as (31) must be due to movement from this low position to C. Given the assumptions underpinning Sailor's argument, insertion of the auxiliary verb must occur before V2 movement, as the latter is assumed to be attraction of $\mathrm{V}$ (not some functional head) by $\mathrm{C}$.

Consider the consequences that this conclusion has for the derivation of $(30,31)$ above. Before $\mathrm{C}$ is merged, VP ellipsis applies, triggering insertion of the auxiliary verb below T: ${ }^{15}$

\footnotetext{
${ }^{14}$ Sailor derives V-stranding VPE in languages such as Hebrew and Russian (i.a. Goldberg 2005, Gribanova 2013) under the assumption that the same head triggers VPE and movement of V out of VP. Since operations triggered by the same head occur in parallel, no bleeding ensues.

${ }^{15}$ For the purposes of the present argument, we do not need make a commitment as to the precise position in which the auxiliary is inserted. We specify this position as V to highlight the fact that it is a verb that can satisfy the V2 requirement. See Houser et al. 2011 for discussion of different alternatives.
} 


$$
\left[\text { TP } \mathrm{T}\left[\mathrm{VP} \mathrm{V}(\mathrm{g} \varnothing \mathrm{re}) \text { tVP }_{\mathrm{VP}} \mathrm{DP}\right]\right]
$$

Since the auxiliary is a verb in a position higher than the lexical verb, the HMC ensures that the auxiliary, not the lexical verb, undergoes head movement to a higher position, resulting in (31) instead of (30). Therefore, the fact that the lexical verb is in the elided constituent does not play a role in accounting for the contrast. Given this, Sailor's assumption that V2 involves a direct relation between $\mathrm{C}$ and $\mathrm{V}$ is not necessary, and a fully cyclic and local derivation is compatible with the data. Specifically, under our GenHM account, the auxiliary undergoes GenHM to T, and the resulting complex head undergoes further GenHM to $\mathrm{C}:{ }^{16}$

$$
\begin{aligned}
& \text { Movement of the auxiliary to } \mathrm{C} \\
& {[\mathrm{CP} V(\mathrm{~g} \emptyset \mathrm{re})+\mathrm{T}+\mathrm{C}[\mathrm{TP} \mathrm{V}(\mathrm{g} \emptyset \mathrm{re})+\mathrm{T}+\mathrm{C}[\mathrm{VP}}
\end{aligned}
$$

As in other V2 sentences, the complex head is spelled out in C, the highest strong position.

In summary, V2 in MSc confirms one of the predictions of GenHM: spellout positions in head chains can be nonadjacent structurally, resulting in complex word order patterns that only apparently involve nonlocal or countercyclic movements of heads.

5. Conclusion. We argued that head raising and lowering are epiphenomenal: they involve respectively high and low spellouts of a single syntactic operation - Generalized Head Movement. Such unification is motivated by the fact that head raising and lowering share fundamental properties: i) they create identical, Mirror-Principle-obeying complex heads (evidenced by the morphophonology of Ndebele relative prefixes) and ii) they both feed further head movement (giving rise to apparent long head movement in MSc). In the proposed theory, lowering is the covert counterpart of head movement, and thus bears a resemblance to covert phrasal movement (under the copy theory of movement). Nonetheless, the current proposal is not an attempt to reduce head movement to phrasal movement (as in Matushansky 2006, for instance). GenHM and internal merge are distinct operations, which create distinct syntactic objects and relations. The parallel between them is only partial, namely in deriving the effect of displacement by copypronunciation rules. Finally, GenHM eliminates the possibility, entertained in previous literature, of placing head raising and lowering in different modules of the grammar - narrow syntax and postsyntax, respectively. Given this, any potential asymmetries between the two cannot stem from the nature of the GenHM operation, and must be viewed as PF phenomena. We leave this question for future work.

\section{References}

Adger, David, Daniel Harbour \& Laurel Watkins. 2009. Mirrors and microparameters: Phrase structure beyond free word order (Cambridge Studies in Linguistics 122). Cambridge: Cambridge University Press.

Aelbrecht, Lobke. 2010. The syntactic licensing of ellipsis (Linguistik Aktuell/Linguistics Today 149). Amsterdam: John Benjamins.

\footnotetext{
${ }^{16}$ In sentences with no V2 (e.g. the bracketed clause in (33)), GenHM only relates T and V, and the complex head is spelled out in VP, as this is the highest strong position in the absence of C.
} 
Baker, Mark. 1985. The Mirror Principle and morphosyntactic explanation. Linguistic Inquiry 16(3). 373-415. http://www.jstor.org/stable/4178442.

Baker, Mark. 1988. Incorporation: A theory of grammatical function changing. Chicago: University of Chicago Press.

Baker, Mark. 2003. Agreement, dislocation, and partial configurationality. In Andrew Carnie, Heidi Harley \& MaryAnn Willie (eds.), Formal approaches to function in grammar: In honor of Eloise Jelinek (Linguistik Aktuell/Linguistics Today 62), 107-132. Amsterdam: John Benjamins.

Bentzen, Kristine, Jason Merchant \& Peter Svenonius. 2013. Deep properties of surface pronouns: Pronominal predicate anaphors in Norwegian and German. Journal of Comparative Germanic Linguistics 16(2-3). 97-125. https://doi.org/10.1007/s10828-013-9057-z.

den Besten, Hans. 1983. On the interaction of root transformations and lexical deletive rules. In Werner Abraham (ed.), On the formal syntax of the Westgermania (Linguistik Aktuell/Linguistics Today 3), 47-131. Amsterdam: John Benjamins.

Bobaljik, Jonathan. 1995. Morphosyntax: The syntax of verbal inflection. Cambridge, MA: MIT dissertation. http://hdl.handle.net/1721.1/11351.

Bresnan, Joan \& Sam A. Mchombo. 1987. Topic, pronoun, and agreement in Chicheŵa. Language 63(4). 741-782. https://doi.org/10.2307/415717.

Brody, Michael. 2000. Mirror Theory: Syntactic representation in Perfect Syntax. Linguistic Inquiry 31(1). 29-56. https://doi.org/10.1162/002438900554280.

Cheng, Lisa. 2006. Decomposing Bantu relatives. In Christopher Davis, Amy Rose Deal \& Youri Zabbal (eds.), NELS 36: Proceedings of the thirty-sixth annual meeting of the North East Linguistic Society, volume one, University of Massachusetts Amhertst, October 28-30, 2005, 197-215. Amherst, MA: GLSA.

Chomsky, Noam. 1957. Syntactic structures. The Hague: Mouton.

Chomsky, Noam. 1993. A Minimalist Program for linguistic theory. In Kenneth Hale \& Samuel Jay Keyser (eds.), The view from Building 20: Essays in linguistics in honor of Sylvain Bromberger (Current Studies in Linguistics 24), 1-52. Cambridge, MA: MIT Press.

Demuth, Katherine \& Carolyn Harford. 1999. Verb raising and subject inversion in Bantu relatives. Journal of African Languages and Linguistics 20(1). 41-62.

Diercks, Michael. 2010. Agreement with subjects in Lubukusu. Washington D.C.: Georgetown University dissertation. http://hdl.handle.net/10822/553142.

de Dreu, Merijn. 2008. The internal structure of the Zulu DP. Leiden: Leiden University MA thesis. http://ling.auf.net/lingbuzz/000916 (28 January, 2018).

Embick, David \& Roumyana Izvorski. 1997. Participle-auxiliary word orders in Slavic. In Wayles Browne, Ewa Dornisch, Natasha Kondrashova \& Draga Zec (eds.), Annual workshop on Formal Approaches to Slavic Linguistics: The Cornell meeting 1995, 210-239. Ann Arbor, MI: Michigan Slavic Publications.

Embick, David \& Rolf Noyer. 2001. Movement operations after syntax. Linguistic Inquiry 32(4). 555-595. https://doi.org/10.1162/002438901753373005.

Emonds, Joseph. 1970. Root and structure-preserving transformations. Cambridge, MA: MIT dissertation. http://hdl.handle.net/1721.1/12969.

Emonds, Joseph. 1978. The verbal complex V'-V in French. Linguistic Inquiry 9(2). 151-175. http://www.jstor.org/stable/4178050.

Giusti, Giuliana. 1997. The categorial status of determiners. In Liliane Haegeman (ed.), The new 
comparative syntax (Longman Linguistics Library), 95-123. London: Longman.

Goldberg, Lotus. 2005. Verb-stranding VP ellipsis: A cross-linguistic study. Montréal: McGill University dissertation. https://sites.google.com/a/brandeis.edu/lotusgoldberg/research (28 January, 2018).

Gribanova, Vera. 2013. Verb-stranding verb phrase ellipsis and the structure of the Russian verbal complex. Natural Language and Linguistic Theory 31(1). 91-136. https://doi.org/10.1007/ s11049-012-9183-3.

Halle, Morris \& Alec Marantz. 1993. Distributed Morphology and the pieces of inflection. In Kenneth Hale \& Samuel Jay Keyser (eds.), The view from Building 20: Essays in linguistics in honor of Sylvain Bromberger (Current Studies in Linguistics 24), 111-176. Cambridge, MA: MIT Press.

Harizanov, Boris \& Vera Gribanova. 2018. Whither head movement? Ms., Stanford University. Henderson, Brent. 2006. The syntax and typology of Bantu relative clauses. Urbana-Champaign, IL: University of Illinois dissertation.

Henderson, Brent. 2007. The syntax of agreement in Bantu relatives. Texas Linguistic Society 9. 167-184. http://web.stanford.edu/group/cslipublications/cslipublications/TLS/TLS9-2005/ TLS9_Complete.pdf (14 January, 2018).

Henderson, Brent. 2013. Agreement and person in anti-agreement. Natural Language and Linguistic Theory 31(2). 453-481. https://doi.org/10.1007/s11049-013-9186-8.

Holmberg, Anders. 1986. Word order and syntactic features in the Scandinavian languages and English. Stockholm: University of Stockholm dissertation.

Holmberg, Anders \& Christer Platzack. 1995. The role of inflection in Scandinavian syntax (Oxford Studies in Comparative Syntax). Oxford: Oxford University Press.

Houser, Michael, Line Mikkelsen \& Maziar Toosarvandani. 2011. A defective auxiliary in Danish. Journal of Germanic Linguistics 23(3). 245-298. https://doi.org/10.1017/ S1470542711000043.

Khumalo, James. 1992. The morphology of the direct relative in Zulu. In Derek Gowlett (ed.), African linguistic contributions: Presented in honour of Ernst Westphal, 210-226. Pretoria: Via Afrika.

Koopman, Hilda. 1984. The syntax of verbs: From verb movement rules in the Kru languages to Universal Grammar. Tilburg: Tilburg University dissertation. https://pure.uvt.nl/portal/ files/1204885/3955255.pdf (21 January, 2018).

Lasnik, Howard. 1981. Restricting the theory of transformations: A case study. In Norbert Hornstein \& David Lightfoot (eds.), Explanation in linguistics: The logical problem of language acquisition (Longman Linguistics Library 25), 152-173. London: Longman.

Lema, José \& María Luisa Rivero. 1990. Long head movement: HMC vs. ECP. In Juli Carter, Rose-Marie Déchaine, Bill Philip \& Tim Sherer (eds.), NELS 20: North East Linguistic Society, 337-347. Amherst, MA: GLSA.

Letsholo, Rose Meleko. 2002. Syntactic domains in Ikalanga. Ann Arbor, MI: University of Michigan dissertation.

Matushansky, Ora. 2006. Head movement in linguistic theory. Linguistic Inquiry 37(1). 69-109. https://doi.org/10.1162/002438906775321184.

Pietraszko, Asia. 2017. Obligatory CP nominalization in Ndebele. http://lingbuzz.auf.net/ lingbuzz/003273 (14 January, 2018).

Platzack, Christer. 1986. COMP, INFL, and Germanic word order. In Lars Hellan \& Kirsti Koch 
Christensen (eds.), Topics in Scandinavian syntax (Studies in Natural Language and Linguistic Theory 5), 185-234. Dordrecht: Reidel.

Pollock, Jean-Yves. 1989. Verb movement, Universal Grammar, and the structure of IP. Linguistic Inquiry 20(3). 365-424. http://dx.doi.org/10.1353/lan.2014.0110.

Sailor, Craig. 2009. Tagged for deletion: A typological approach to VP ellipsis in tag questions. Los Angeles: University of California MA thesis. http://www.craigsailor.net/papers/sailor thesis_10-3-11.pdf (14 January, 2018).

Sailor, Craig. To appear. The typology of head movement and ellipsis: A reply to Lipták and Saab (2014). Natural Language and Linguistic Theory. https://doi.org/10.1007/ s11049-017-9391-y.

Schneider-Zioga, Patricia. 2007. Anti-agreement, anti-locality and minimality: The syntax of dislocated subjects. Natural Language and Linguistic Theory 25(2). 403-446. https://doi. org/10.1007/s11049-006-9014-5.

Sibanda, Galen. 2004. Verbal phonology and morphology of Ndebele. Berkeley, CA: University of California dissertation. http://escholarship.org/uc/item/6cf9w3j2.

Stabler, Edward. 2001. Recognizing head movement. In Philippe de Groote, Glyn Morrill \& Christian Retoré (eds.), Logical Aspects of Computational Linguistics 4th International Conference, LACL 2001 Le Croisic, France, June 27-29, 2001 Proceedings (Lecture Notes in Artificial Intelligence 2099), 245-260. Berlin: Springer.

von Staden, P.M.S. 1973. The initial vowel of the noun in Zulu. African Studies 32(3). 163-181. https://doi.org/10.1080/00020187308707406.

Svenonius, Peter. 2016. Spans and words. In Daniel Siddiqi \& Heidi Harley (eds.), Morphological metatheory (Linguistik Aktuell/Linguistics Today 229), 201-222. Amsterdam: John Benjamins.

Taraldsen, Knut Tarald. 1985. On verb second and the functional content of syntactic categories. In Hubert Haider \& Martin Prinzhorn (eds.), Verb second phenomena in the Germanic languages (Publications in Language Sciences 21), 7-25. Dordrecht: Foris.

Taraldsen, Knut Tarald. 2010. The nanosyntax of Nguni noun class prefixes and concords. Lingua 120(6). 1522-1548. https://doi.org/10.1016/j.lingua.2009.10.004.

Thoms, Gary. 2012. Verb movement and ellipsis in Scandinavian. Ms., University of Edinburgh.

Travis, Lisa deMena. 1984. Parameters and effects of word order variation. Cambridge, MA: MIT dissertation. http://hdl.handle.net/1721.1/15211.

Vikner, Sten. 1995. Verb movement and expletive subjects in the Germanic languages (Oxford Studies in Comparative Syntax). Oxford: Oxford University Press.

Visser, Marianna. 2008. Definiteness and specificity in the isiXhosa determiner phrase. South African Journal of African Languages 28(1). 11-29. http://www.tandfonline.com/doi/abs/ 10.1080/02572117.2008.10587298.

Zeller, Jochen. 2004. Relative clause formation in the Bantu languages of South Africa. Southern African Linguistics and Applied Language Studies 22(1-2). 75-93. https://doi.org/10.2989/ 16073610409486361. 